\title{
LA PRUDENCIA POLÍTICA EN TOMÁS DE AQUINO
}

\author{
Alberto Cárdenas $P$. \\ Universidad Santo Tomás
}

\section{Resumen}

En el artículo se hace un recorrido por la historia de los vocablos -y sus significadosque dan lugar al concepto de prudencia. Desde el mito de Prometeo y la prometheia, pasando por filósofos y pensadores griegos (la fronesis y su adaptación en los romanos como providentia), hasta el tratado de la prudencia en Tomás de Aquino, donde se asume como intersección de los dinamismos morales e intelectuales, y fundamentalmente como inteligencia práctica, clave de la ética en cuanto dirige la elección e impera la acción en orden a la perfección del ethos humano. De esta forma se llega a la prudencia política en Tomás de Aquino: sus partes integrantes y sus clasificaciones. Se estudia especialmente la prudencia gubernativa, con sus especificaciones (prudencia del régimen, legislativa, de justicia y militar) y la prudencia política propiamente dicha o de los súbditos, en la cual se distingue la de los ciudadanos y la de los grupos restringidos.

\section{Palabras clave}

Tomás de Aquino, prometheia, fronesis, providentia, jurisprudencia, prudencia política.

\section{Abstract}

In this article a journey is made by the history of the words -and its meanings. that give place to the concept of prudence. From the myth of Prometeo and the prometheia, going by philosophers and Greek thinkers (the fronesis and their adaptation in the Romans as providentia), until the treaty of the prudence in Thomas of Aquino, where it is assumed as intersection of the moral and intellectual dynamisms, and fundamentally as practical intelligence, key of the ethics that directs the election and governs towards the perfection of the human ethos.

In this way you arrive to the political prudence in Thomas of Aquino: their integral parts and their classifications. It is especially studied the governmental prudence, with their 
specifications (prudence of the régime, legislative, of justice and military) and the properly political prudence of the citizens, in which is distinguished that of the citizens and that of the restricted groups.

\section{Key words}

Thomas of Aquino, prometheia, fronesis, providentia, jurisprudence, political prudence.

Ipse (homo) est sibi providens

Tomás de Aquino

\section{La prudencia entre los griegos y romanos}

\subsection{El mito de Prometeo y la prometheia}

El mito era recurso didáctico colectivo — como en casi todas las grandes culturas - también de la paideia griega, a fin de asegurar la permanencia de las tradiciones y del modo de ser helénico. Para enseñar la importancia de estar atentos a los grandes desafíos de la vida y la necesidad de saber elegir lo mejor, se recurría al mito machista de Prometeo, según el cual una de las primeras elecciones cruciales tienen que ver con la mujer, "el bello mal”, en palabras de Hesíodo, el poeta beocio de la Teogonía y de Trabajos y días, quien escribe hacia finales del siglo VIII a. C. En las dos obras alude al mito de Prometeo, cuya altanera sabiduría irrita a Zeus, pero cuya previsión práctica le evita caer en la seducción de Pandora. El nombre del hijo de Jápeto se relaciona directamente con las palabras griegas prometheia (previsión, cuidado, atención), prometheomai (cuidar, velar), promethés (previsor, que se inquieta de antemano, que observa y piensa antes de actuar).

Pandora (que significa "todos los regalos”) fue la primera mujer. Vulcano la formó con lodo y en cuanto acabó de modelarla, la exhibió ante los demás dioses del Olimpo, que se apresuraron a otorgarle sendos dones. Júpiter también le dio el suyo: una caja con todos los males y le ordenó que fuera donde Prometeo y se casara con él. Pero éste, después de observarla detenidamente, pensó que no era conveniente apresurarse y le encareció a su hermano Epimeteo ser igualmente cuidadoso. Éste, sin embargo, desatendió el consejo y no sólo aceptó como esposa a Pandora, sino que tomó la caja y la abrió. Escaparon inmediatamente todos los males que afligen a la humanidad. Sólo quedó en el fondo la Esperanza. Epimeteo —que significa "el que piensa después"- se arrepintió de lo hecho, pero ya era demasiado tarde.

El mito de Prometeo se fue convirtiendo en el símbolo más profundo de la ética, en cuanto reflexión crítica sobre el ethos o carácter del hombre griego, adquirido por el hábito de la prometheia, reguladora de la vida moral, la vida religiosa, la vida política, la vida "económica" o familiar. Prometeo ("el que piensa previamente”) era el previsor, providente, que había robado a los dioses su propia Providencia. La actitud promética equivalía a afirmar la autonomía del hombre en la realización de sí mismo. De esa manera, ya en el siglo V, por ejemplo, con 
Sócrates, las virtudes morales se reducían a la frónesis (de fren = razón, pensamiento, memoria), término sinónimo de prometheia, al que va a terminar por desplazar.

\subsection{Frónesis, providentia y prudentia}

En Sócrates, Platón, Jenofonte, Esquines, el significante que se impone no es prometheia sino frónesis, para significar espíritu, mente, inteligencia, conocimiento, sabiduría, nobleza, magnanimidad, propósito, buen juicio, temple, ánimo, confianza en sí mismo... A lo largo del siglo V, su campo semántico abarca en especial estas capacidades estables: conocimiento del valor y del bien, espíritu animoso, saber elegir lo más valioso, conocimiento de los bienes supremos, conocimiento de la causa última del universo. Pero a partir de Aristóteles, aun conservando la polisemia anterior, frónesis se refiriere cada vez más, no tanto a la vida contemplativa y a la comprensión teórica, sino a la vida activa y al entendimiento práctico, al mundo de las elecciones cotidianas, en cuyo tráfico es preciso poseer buen juicio, temple, confianza en sí mismo para saber elegir lo que resulte más conveniente para activar o mantener la felicidad.

Aristóteles, en la Ética a Nicómaco, después de hablar de la virtud en general, de las virtudes que dan sentido humano a la parte irracional (fortaleza y templanza), de las virtudes del apetito racional que es la voluntad (libertad, magnificencia, magnanimidad, mansedumbre, eutrapelia, etc.) y sobre todo de la justicia, en el libro VI pasa a hablar de las virtudes de la inteligencia en su doble función teorética y práctica. Después de analizar las virtudes de la primera función, se detiene a explicar la diferencia entre poiein ("hacer") y práttein (“obrar”), aspectos de la acción humana a los que corresponden las virtudes de la inteligencia práctica: téjne (“arte”), hábito operativo de la producción, y frónesis, hábito operativo encaminado a guiar el "obrar" para perfeccionar el ethos del hombre, con el fin de estabilizar su felicidad.

"Lo propio del hombre de frónesis - dice Aristóteles- parece ser el poder deliberar acertadamente sobre las cosas buenas y provechosas para él, no parcialmente, como cuáles son buenas para la salud o el vigor corporal, sino cuáles lo son para el bien vivir en general”. Y continúa haciendo precisiones: nadie delibera sobre cosas que no pueden ser de otra manera, ni sobre las que no puede él mismo hacer; mientras el poiein (hacer) tiene otro fin distinto de la misma operación, el práttein (obrar) no lo tiene, ya que la misma buena acción es su fin; la frónesis integra las demás virtudes, y, aunque no puede cerrarse a lo universal, apunta a conocer las circunstancias particulares, porque se ordena a la acción, que tiene como materia precisamente lo singular y particular; existen varias frónesis: la propia del individuo, la de la familia (“económica”) y la política; los jóvenes llegan a ser matemáticos en poco tiempo, pero no alcanzan fácilmente la frónesis, pues al versar ésta sobre lo táctico variable, no llega a convertirse en habitual sino tras larga experiencia; la frónesis concierne al orden del devenir y se relaciona con el buen consejo, la comprensión, la penetración, la consideración, la equidad; la frónesis es imperativa, pues su fin consiste en determinar lo que debe o no hacerse...

La frónesis de los griegos se traslada, entre los romanos, al campo semántico de providere (ver delante de sí, ver de lejos, prever, proveer, velar por...), pro-visio (previsión y provisión), pro-videntia (cuidado, cautela, previsión, provisión). Este último sustantivo se contrae en la forma prudentia, que, en el lenguaje de Cicerón y de los juristas, pasa a significar inteligencia práctica, ingenio, 
conocimiento, por ejemplo y de manera paradigmática, para aplicar el derecho. El campo semántico jurídico, el campo del ius y de la lex, entra en intersección con el de providere $\mathrm{y}$, de esa manera, se empieza a hablar de juris-prudentia, "juris-prudentes" o "prudentes" a secas, y de "providencias": se piensa que la "prudencia" debe ser la disposición por excelencia del hombre de derecho; a él corresponde tener el "conocimiento de las cosas divinas y humanas y la ciencia de lo justo y de lo injusto", es decir, la juris-prudentia, el saber sobre las distintas formas de interferencia intersubjetiva y la capacidad de "responder", "precaver" y "actuar" para promover la justicia, alma de la convivencia. Entre los “prudentes", el derecho deja de ser imperativo inflexible del orden público, la regla impuesta y absoluta; su fundamento no es ya la autoridad, sino la razón práctica, atenida a la "naturaleza de la cosa”. Esta es referente necesario de toda providentia o decisión para agilizar la causa o para resolver peticiones... Todavía hoy hablamos de "providencias", aunque ni a los jueces ni a los abogados se les forme en la universidad para la "prudencia".

Desde entonces, la "prudencia" alude a la previsión racional, resultado de la inferencia o deducción que se basa en la noticia del pasado, en el saber recibido de los "prudentes" y en el conocimiento de las circunstancias del presente; pero no se queda en el conocimiento, pues debe llevar a elegir y a imperar la acción. De raíz intelectiva, es un hábito que impulsa el obrar en el sentido de la "vida buena". Esta tradición nocional se traslada a la mentalidad y a las ideas de los medievales, traducida por el imaginario escultórico mediante las cabezas de doble rostro: rostro de anciano que mira al pasado y rostro de doncella que mira, confiada y esperanzada, hacia el porvenir. El prudente cristiano, adoctrinado por el imaginario de las catedrales, aprendía a cultivar las dos miradas al asumir los desafíos del presente.

\section{El "providente" y "prudente" tomás de aquino}

Saltando de griegos y romanos al integralista Tomás de Aquino, hallamos a un hombre convencido de que la grandeza sustancial del ser humano es que ipse est sibi providens: señor de sí mismo, que puede proveerse por sí y proyectar su propio destino, como explicaba Juan Pablo II en la Universidad Santo Tomás de Roma, en noviembre de 1979. Se siente uno tentado a recuperar cuanto simboliza el mito de Prometeo: afirmar la autonomía del hombre en la realización de sí mismo. El hombre tiene en sus manos lo que quiere llegar a ser. A él le corresponde "inventarse", en el sentido de buscarse, encontrarse, identificarse, y recrearse. La revista Cromos nos recuerda una afirmación de Gabriel García Márquez: "Los seres humanos no nacen para siempre el día en que sus madres los alumbran, sino que la vida los obliga a parirse a sí mismos una y otra vez"'. No obstante, hay que hacerle precisiones al prometeico Nobel: ese parto que uno hace de sí mismo no puede negar la naturaleza humana ni puede ser autotélico, enteramente liberado a fines caprichosos, como medida subjetiva de todas las cosas, especialmente de todas sus cosas. Se correría el riesgo de autoparir "un ridículo ratón”, un triste subhumano o un monstruo. El ipse sibi providens de Tomás cuenta con Dios y con el estatuto de la propia naturaleza. El papel de la existencia es realizar las posibilidades de la esencia, para no "mal-parirse" como un auténtico "aborto moral”.

Cromos, 23 de febrero de 2005. 
Para evitar autopartos sin fecundidad humanizante, el providens Tomás de Aquino da centralidad a la "providencia" o "prudencia”, que une racionalidad y novedad situacional. Está convencido de que, a pesar de que el hombre puede "hacerse todas las cosas" por medio de su inteligencia, el dominio de la realidad al que accede, por su limitación y fínitud, es un dominio inestable y mudable. Su verdad, adecuación a las cosas, no goza de la inmutabilidad de la verdad divina, como afirma en la q. 16, a. 8 de la I parte de la Suma Teológica. "Si hay algún entendimiento - escribe Tomás- en el que no pueda darse un cambio de opinión, o al que no se le escape nada, en él la verdad es inmutable. Un entendimiento así lo es el divino... En cambio, la verdad de nuestro entendimiento es cambiable. No porque ella esté sometida a mutación, sino porque nuestro entendimiento pasa de la verdad a la falsedad”. Y, al no tener sino una aproximación cambiante a la realidad, que hay que estar corrigiendo, la vida del hombre resulta acosada por la incertidumbre. Pero precisamente el dinamismo de la "prudencia" consiste en ver y prever a través de la incertidumbre, como sostiene Tomás citando a Isidoro de Sevilla (q. 47 de la II-II).

Continúa Tomás explicando que la "prudencia”, a pesar de la incertidumbre, no es una adivinación, una sensación, una intuición, aunque no se descarten esos componentes de la "cogitativa" prerracional. En sus palabras, "conocer el futuro a través del presente o del pasado, que es lo propio de la prudencia, concierne al entendimiento, puesto que se hace por deducción” (q. 47 de la II-II). Es cierto que funciona en la intersección de los dinamismos morales y de los dinamismos intelectuales, pero su naturaleza es la de la inteligencia práctica que, hic et nunc, dirige la elección e impera la acción.
La prudencia, aunque ante todo asume los signos del presente, integra éste dentro de toda la derivación o sucesión temporal: conecta el presente con el pasado y apresta para asumir el futuro, que de los tres tiempos es el más incierto. El presente es más o menos confuso y el pasado goza de mayor certeza. Por ello, el prudente, al elegir no puede hacer caso omiso de las lecciones del pasado y de quienes han vivido más. El prudente es un proyectista — de ahí la importancia de la prospección-, pero el verdadero proyecto prudencial debe contar siempre con la realidad, apoyarse en las cosas, que, al ser comprendidas en la perspectiva de los tres tiempos, nunca resultan las mismas en todas las situaciones. La razón práctica prudencial, por la aparente inestabilidad de su objeto, debe gozar de flexibilidad, de aptitud para readaptarse. La prudencia es "cognoscitiva” de una realidad en devenir y "preceptiva" de una acción conforme a la realidad, que debe gozar de "acierto al empezar, dirección al progresar y perfección al acabar" — como oraba Tomás- para producir bienes concretos. La prudencia no consiste en un abstracto imperativo categórico, sin importar cuáles sean sus efectos en el orden del ser: lo que importa es ir guiando nuestra vida, realizar nuestra vocación en el mundo, ayudar eficazmente a los demás, mejorar objetivamente la realidad en la que vivimos.

Tomás, al elaborar su "Tratado de la prudencia” en la Suma Teológica, integró tres tipos de fuentes: Sagrada Escritura, citada 84 veces; Santos Padres (Ambrosio, Jerónimo, Agustín, Gregorio, Isidoro, Pseudo Dionisio), citados 40 veces; filósofos (Aristóteles, Andrónico, Cicerón, Macrobio, Terencio, Valerio Máximo), citados 117 veces. Las citas más abundantes son aristotélicas, bíblicas y agustinianas. Si Aristóteles fue el primero que, entre los grie- 
gos, delimitó la frónesis frente a otras virtudes intelectuales o dianoéticas, el articulador sintético que fue Tomás elaboró con los tres tipos de fuentes mencionadas el primer tratado digno de tal nombre en su época. Un tratado que es todo un fuerte lazo trenzado con las tres resistentes cuerdas mencionadas (Escritura-Padres-Filósofos), al cual podemos asirnos para no precipitarnos al vacío de la insensatez o de la improvisación, pues nos enseña a permanecer bien atados a la roca de la realidad.

La herencia cristiana de Tomás lo había convencido de que la "prudencia” (providentia sui) era la virtud quicial del mundo ético por ser el alma, la forma, la madre, la maestra, la directora y moderadora de todos los demás dinamismos éticos o poderes (virtudes) operativos en la tarea de la construcción del propio carácter y del modo de ser colectivo; pero la tradición cristiana enseñaba también que la "prudencia" no es sólo conciencia de que vivimos en la incertitudo, sino que nos habitúa igualmente a prever cuándo nos hallamos cercados de acechanzas y amenazas externas o rodeados de reales y potenciales enemigos. En Mateo 10, 16, Jesús había advertido a sus apóstoles que eran enviados “como ovejas en medio de lobos", y que debían ir sin miedo y hacerse frónimoi (prudentes) como las serpientes y akéraioi (puros, sinceros) como las palomas. Las serpientes no se engañan, porque se deslizan sobre la tierra (realidad) y pueden distinguir sus accidentes; mas es necesario también el sobrevuelo — sin intención predatoria ni carroñera - de las palomas, para el reconocimiento y control de su propio paisaje, lo que les proporciona claridad. La frónesis cristiana no puede ser ingenua sobre las posibilidades de acción en situación, pero no puede ser dolosa (con dolus malus), negando las interconexiones del conjunto.
Alberto Magno se había preocupado por la complejidad del dinamismo ético de la prudencia; pero fue su discípulo Tomás el que logró pensarla como un todo con distintas partes armónicamente ensambladas, teniendo en cuenta como patrón de organización tanto sus funciones cognoscitiva y directiva como el aspecto tritemporal. La actividad prudencial parte del presente con una mirada al pasado (memoria de las experiencias adquiridas, propias o ajenas); vuelve al presente como visión clara de la situación (inteligencia o entendimiento de lo particular o singular, búsqueda de sentido); vuelve indirectamente al pasado, al recurrir al consejo de los sabios y de los que han vivido más (docilidad o apertura a opiniones autorizadas); vuelve al presente y atiende con prontitud a las coyunturas ("solercia” o agilidad mental repentizadora o inventiva, necesaria especialmente cuando la urgencia no permite consultar); sigue en el presente investigando, indagando, avanzando en comprensión (razón como meditación y juicio razonable); continúa en el presente, pero mirando hacia el futuro, buscando relacionar fines y medios, previendo las contingencias del porvenir (providentia, que incluye el ver de lejos, anticiparse a lo que vendrá y proveer lo necesario); vuelve al presente en atenta consideración de todas las circunstancias, tratando de aprovechar las oportunidades (circunspección); equilibrio entre presente y futuro al acercarse al momento de elegir de manera definitiva e imperar la acción (precaución o cautela), previendo lo que extrínsecamente podría llegar a impedir lo que se quiere, sobre todo contando con el hecho de que las apariencias engañan, dada la complejidad de la realidad. Todo el proceso debe estar acompañado por la convergencia del "buen consejo” (eubulia) o capacidad de descubrir alternativas o posibilidades, el "buen juicio" (synesis) o sensatez para discernir lo más 
conveniente y la gnome o perspicacia para definir excepciones a las reglas comunes.

De acuerdo con el aparato prudencial descrito (organon prudentiae), la situación y las circunstancias de cada caso nos llevan a reinventamos, a perfilarnos de nuevo; pero eso no significa que no haya principios y normas éticas universales. Son estos precisamente los que generan el esfuerzo de la memoria, del pedir consejo, de la sensatez, de la precaución, etc. No podemos autoparirnos de cualquier manera, partiendo de cero. Se atribuye un valor efectivo a la variedad de las situaciones humanas, pero sin olvidar el núcleo permanente del recto vivir humano. Nuestra razón práctica ha de determinar en cada caso lo que hemos de hacer para actuar en consonancia con las exigencias de los otros dinamismos éticos: temperancia, fortaleza, justicia. El dinamismo ético de la prudencia es la disposición operativa necesaria para que los fines de estas virtudes se cumplan y no de forma eventual, sino precisamente habitual, de tal manera que se estabilice el propio carácter como generador permanente de respuestas valiosas. El objeto propio de la ética no son los actos tomados uno a uno, sino el ethos integral que define la vocación humana de cada uno. Mientras no se posea la prudencia, integradora estable de todas las virtudes, ningún hombre tendría inclinación al recto comportamiento en todas las ocasiones, así se equivoque muchas veces.

Por esa razón, Tomás afirma la supremacía de la prudencia. Ella “domina” a las demás virtudes porque se especializa en conocer la realidad objetiva. "Lo primero que se exige de quien obra es que conozca”, afirma el Aquinate. Quien ignora cómo son verdaderamente las cosas en cada situación no puede obrar bien, pues esto supone verdad, y ésta no se da sino en conformidad con la realidad. Conocida la realidad, de acuerdo con el aparato cognoscitivo prudencial, pueden realizarse los fines de la justicia, de la fortaleza o de la temperancia. Se supone que el justo es dueño de sus deberes, que el fuerte es dueño de sus temores y que el temperado es dueño de su capacidad de placer; pero todos esos dominios personales hacen variar las acciones según el conocimiento de la realidad que va proporcionando la prudencia, encargada de proveer los medios adecuados.

Escribe Tomás: "La prudencia es la virtud más necesaria para la vida humana. Efectivamente, vivir bien consiste en obrar bien, pero para que uno obre bien no sólo se requiere la obra que se hace, sino también el modo de hacerla, esto es, que obre conforme a recta elección, y no por impulso o pasión. Mas como la elección es respecto de los medios para conseguir un fin, la rectitud de la elección requiere dos cosas, a saber: el fin debido y el medio convenientemente ordenado al fin debido...; y respecto del medio adecuado al fin debido, necesita el hombre disponerse directamente mediante el hábito de la razón, ya que el deliberar y elegir, que versan sobre los medios, son actos de la razón. Por consiguiente, es necesario que en la razón exista alguna virtud intelectual que la perfeccione convenientemente respecto de los medios a elegir para la consecución del fin, y tal virtud es la prudencia”. (S.T. I-II, 57,5).

Existe en Tomás una “ontología”, cuya tipología reúne más de veinte términos, que se relaciona especialmente con quienes no han alcanzado la autonomía inteligente de la prudencia. Su razón práctica resulta embotada, incapaz de conocer la realidad y, por tanto, de discernir lo bueno. La prudencia es el signo de la mayoría de edad, expresión de la libertad, precisamente porque es un poder estable de adecuar las decisiones a las circunstancias que van reclamando justicia, fortaleza o templanza, o todas a la vez. Éstas le 
dan contenido o materia a la prudencia, pero ésta tiene sobre ellas la primacía visiva, previsiva y provisiva. En este todo dinámico de las virtudes unificadas por la prudencia consiste la libertad moral de que carecen todos los tontos, que obran generalmente por temor y sin autonomía creativa.

Si alcanzar la prudencia fue la meta de la educación durante la Edad Media, después del Renacimiento su ensamblaje se fue desintegrando y algunos aspectos se hipertrofiaron gradualmente. Pasando por Maquiavelo (1469-1527) hasta llegar a Baltasar Gracián (1601-1658, Oráculo manual y arte de prudencia), la prudencia se va entendiendo más como astucia, cautela, simulación y dolo, para no comprometerse en ninguna situación. Perdiendo lo que tenía de audacia creativa y responsable en situación, pasa a significar el arte de escurrir el bulto, de no correr riesgos. Por eso, Kant la desecha de su ética, al considerarla mera habilidad pragmática para ejercer influjo sobre los otros, para utilizarlos conforme a los propios designios de bienestar privado.

Llama la atención que hoy un Fernando Savater (2003) se sienta urgido a escribir acerca de El valor de elegir, que no es sino un nuevo tratado de frónesis. Después de preguntarse: ¿qué es lo que define al ser humano?, se responde que "no son los instintos o nuestra situación genética, tan semejantes a los de otros animales, sino nuestra capacidad de decidir e inventar acciones que transforman la realidad... y a nosotros mismos”2. A tal disposición no la llama precisamente prudencia - término desgastado y con muchas connotaciones que ya no dicen lo que era la frónesis ni la vieja "prudencia” tomista-, sino "libertad" a secas. Los dos epígrafes del libro anuncian lo que será el desarrollo discursivo: "El problema de la elección, el problema de la vida entera” (Georges Perec); “Todos estamos determinados por el hecho de que hemos nacido humanos y, en consecuencia, por la tarea interminable de tener que elegir constantemente, tenemos que elegir los medios juntamente con los fines. No debemos confiar en nadie que nos salve, sino conocer bien el hecho de que las elecciones erróneas nos hacen incapaces de salvamos” (Erich Fromm).

\section{La prudencia política tomasiana}

Así como la persona necesita la prudencia para conducir racionalmente su propia vida (ver, juzgar y actuar), de igual manera los sujetos colectivos requieren formas propias de prudencia para orientar su propia "voluntad” y su “obrar” de realidades relacionales. Las "prudencias colectivas” evitan que los fines comunitarios o sociales se ejecuten a ciegas, pues toda "prudencia” impone conocer la realidad y, a partir de ese conocimiento, determinar lo que se debe o no se debe realizar. La "prudencia" no halla bienes si no descubre primero las cosas que fundan las verdades del quehacer práctico. El deber que establece la "prudencia" está determinado por el ser. Negar la principalidad de la “prudencia” es caer en el espontaneísmo o en el voluntarismo del poder. La realización de la justicia - que es fenómeno de convivencia - no puede soslayar la presencia de la prudencia, que es previo y concomitante conocimiento objetivo de lo que pide la realidad social. Sólo la objetividad puede garantizar que se dé su derecho a cada uno. La justicia sin prudencia produce injusticia.

2 Fernando Savater, El valor de elegir (Barcelona: Ariel, 2003). 
En la q. 48, 1 de la II-II, Aquino clasifica las prudencias según los sujetos. Después de señalar las partes integrales de la prudencia y distribuirlas según los tres momentos del conocimiento, explica: "son partes de la prudencia en sentido propio, la prudencia con que cada cual se gobierna a sí mismo y la prudencia ordenada al gobierno de la multitud; una y otra son específicamente distintas... La prudencia que gobierna la multitud se diversifica, a su vez, según las especies distintas de multitud. Hay, en primer lugar, una multitud congregada en orden a un negocio particular, como el ejército se reúne para luchar, y de ello se encarga la prudencia militar; otra multitud se forma para toda la vida, como es la casa o familia, y ésta se rige por la prudencia económica; o la agrupación de una ciudad o de una nación, para cuya dirección reside en el jefe la prudencia de gobierno; en los súbditos, en cambio, la prudencia política propiamente dicha”.

En la q. 50, arts. 1, 2 y 3, da un orden a la clasificación anterior así: prudencia gubernativa o regnativa, prudencia política, prudencia económica y prudencia militar. De la primera escribe: "La función propia de la prudencia es dirigir y mandar. De ahí que donde hay razón especial de régimen o imperio de los actos humanos, hay también razón especial de prudencia. Ahora bien, resulta evidente que existe razón especial y perfecta de régimen en quien no sólo debe regirse a sí mismo, sino también a la comunidad perfecta de una ciudad o de un reino. En efecto, la república es tanto más perfecta cuanto más universal, extendiéndose a más cosas y llegando a un fin más elevado. De ahí que, por una razón especial y perfectísima, atañe la prudencia al rey, a quien incumbe regir la ciudad o el reino. Por eso entre las especies de prudencia se enumera la regnativa”.
Y de la prudencia política o de los súbditos, precisa en el art. 2: "El siervo es movido por su señor por el imperio, igual que el súbdito por el jefe, pero de modo distinto a como son movidos los animales irracionales y los seres inanimados por sus respectivos principios motores. En efecto, tanto los unos como los otros son solamente impelidos, pero no se conducen por sí mismos, ya que carecen del dominio de sí por medio del libre albedrío... En cambio, los siervos y cualquier clase de súbditos son regidos por el mandato de otro, pero moviéndose ellos libremente. Por eso necesitan la rectitud del gobierno para regirse ellos mismos en la obediencia a los príncipes. Esa es la función propia de la especie de prudencia llamada política”.

La prudencia política de los subordinados es, pues, el correlato necesario a la prudencia gubernativa, y no se trata de una prudencia obediencial pasiva, pues "todo hombre, al ser racional, debe participar en las directrices del gobierno según el juicio de su propia razón” (q. 47, a. 12). Esto lleva a pensar que la gobernabilidad, como posibilidad de gobernar con eficacia, supone la gobernabilidad como aptitud para ser gobernados o voluntad de sujeción de los súbditos. Lo que equivale a decir que no hay gobemabilidad en sentido activo por parte del gobierno sin la correspondiente legitimación por parte de los gobernados. Afirma Tomás que la prudencia del gobernante es "arquitectónica" o constructiva del todo social y que la prudencia de los súbditos es "ejecutora de un plan" (q. 47, 12 ), pero ya se sabe que los ejecutores deben discernir el valor del plan y llevarlo a cabo libremente. La potestas del gobernante resulta anulada sin el apoyo realizativo de la potentia o fuerza activa de la multitud.

En el Comentario a la Ética, L. VI, lec. VI, Tomás explica que la "prudencia arquitectó- 
nica” del gobernante se llama también “compositiva o determinativa de la ley": "Pues se denomina arte arquitectónico el que determina lo que debe ser realizado por los demás. De ahí que los gobernantes, que dictan leyes a sus súbditos, se hallen en lo concerniente a la civilidad como los arquitectos en lo hecho o fabricado. Por ello, componer la ley, o sea, la recta razón según la cual los gobernantes dictan leyes rectas, es llamada prudencia arquitectónica”. En este caso, la prudencia política de los ciudadanos se encarga de "la aplicación de la ley universalmente instituida a lo particular operable”.

Teniendo en cuenta lo anterior y lugares concordantes, se puede concluir con esta clasificación de la prudencia política, género que articula estas especies: prudencia gubernativa o regnativa (del régimen, arquitectónica o legislativa, de la justicia y militar); prudencia política propiamente dicha, que corresponde a quienes constituyen el cuerpo social de la polis o del pueblo; y prudencia de los grupos restringidos intrapolíticos, que se rigen, por analogía, con criterios de "prudencia económica” o de la casa (oikos).

\subsection{Prudencia gubernativa}

Si, de acuerdo con el Aquino, el punto de partida de toda prudencia es el conocimiento de la realidad, antes que el pensar sobre ella, y que ese conocimiento debe arrancar con tres mínimos -lo que las "cosas pasadas" sugieren ("memoria”), lo que las “cosas presentes” indican ("inteligencia”) y lo que las “autoridades” enseñan (“docilidad”), el ejercicio de la prudencia gubernativa deberá comenzar también por ese triple conocer, recuperando el pasado del saber político, atendiendo a lo que los hechos políticos presentes reclaman y aprendiendo de los maestros de la política (de ayer y de hoy).

\subsubsection{Del régimen}

Fundándose en los tres conocimientos, Tomás se eleva a la condición de consejero de prudencia gubernativa y esboza una comprensión de totalidad de la realidad política, que podría concretarse en estos principios y reglas: 1) El hombre es animal social y político por naturaleza; 2) frente al homo homini lupus del comediógrafo Plauto (s. III-II a. C.), es .preciso afirmar que "el hombre es para todo hombre un familiar y amigo” (Omnis homo omni homini familiaris et amicus) (S.T., II-II, 114, 2; Contra Gentiles, IV, 54); 3) esa tendencia amistosa se concreta en la "amistad de los conciudadanos" (amicitia concivium), fundada en la "comunión civil" (communicatione civili) (II-II, 26, 8); 4) el bien de los conciudadanos es un bien de comunión o bien común; 5) “el bien común es el fin de las personas singulares que existen en comunidad, como el fin del todo es el fin de cualquiera de sus partes” (S.T. II-II, 58, a. 9); 6) el bien común - aquel aspecto del bien personal que sólo en común puede alcanzarse- está integrado por tres tipos fundamentales de fines o bienes: la unidad de la paz y la seguridad de los súbditos, poder obrar virtuosa y libremente, "suficiencia de los bienes corporales, cuyo uso es indispensable para una acción virtuosa” (De Regno, I, 16); 7) todos los regímenes políticos que buscan el bien común (monarquía, aristocracia, democracia) pueden ser adecuados según las circunstancias, pero el régimen mixto es preferible cuando todos han adquirido el hábito de la prudencia “política”.

\subsection{2 “Arquitectónica” o legislativa}

La prudencia gubernativa se torna "arquitectónica” y entonces debe ceñirse a estos principios de la experiencia histórica y del saber recibido: 1) los instrumentos jurídicos de construcción social son dos: las normas generales de la autoridad y la costumbre, naci- 
da espontáneamente de la vida social y heredadas de "nuestros antepasados" (I-II, 97, 3); 2) la autoridad tiene el derecho-deber de promulgar leyes como determinaciones de la ley natural, para el bien común y para el cuidado de la comunidad; 3) el príncipe no está sometido a la vis coactiva de las leyes, pero sí a su vis directiva; 4) el fin de las normas jurídicas es "ayudar a los hombres a hacerse buenos” (I-II. 95, 1); 5) aunque nadie se hace bueno por temor, las normas deben ser coactivas y coercitivas porque hay siempre un número relevante de individuos mal dispuestos, rebeldes e inclinados al vicio, contra quienes es preciso utilizar la fuerza y el temor (I-II, 95, 1); 6) éstos últimos, al acostumbrarase por la fuerza a comportarse honestamente, podrán llegar a cumplir libremente (voluntarie) lo que antes hacían por miedo (I-II, 95, 1); 7) las leyes de validez general ayudan a coordinar las relaciones sociales con el fin de hacer posible que los ciudadanos “prevean” cuál será el comportamiento de los demás en determinadas situaciones (I-II, 95, 2); 8) las leyes se dictan basándose en lo que ocurre o puede ocurrir en la mayor parte de los casos (I-II, 96, 6); 9) las leyes deben adecuarse a la condición de los hombres a los que se dirigen $\mathrm{y}$, por ello, no deberán prohibir todos los vicios, sino los "más graves, de los cuales es más posible abstenerse a la mayor parte de los hombres, especialmente aquellas cosas que son para el perjuicio de los demás, sin cuya prohibición la sociedad no se podría conservar, como son los homicidios, hurtos y otros vicios similares” (I-II, 96, 2); 10) la ley no debe mandar todos los actos de todas las virtudes, sino sólo los que tienen una relación directa con el bien común (I-II, 96, 2); 11) no hay que hacer un uso excesivo de leyes positivas, porque eso extiende el temor y puede generar una reacción violenta como cuando aumenta la presión del agua represada
(De Regno, I, 10); 12) todo el pueblo debe controlar que las leyes sean para utilidad común (I-II, 105, 2).

\subsubsection{De la justicia}

Tanto a la prudencia gubernativa como a la política corresponde servir a los fines de la justicia, que es el cometido del "nosotros" de la república, pues por medio de su accionar alteritivo se produce el bien común: conjunto de condiciones externas (paz, abundancia de bienes) que posibilitan tanto la permanencia de la sociedad como el desarrollo de la vida personal y de las comunidades en que ésta se inserta. Pero la prudencia en la realización de la justicia debe guiarse por algunos principios y criterios prácticos decantados por la historia y la reflexión autorizada: 1) "Es preciso que el fin de la comunidad coincida con el del individuo" (De Regno, 1,15); 2) por ello, existen dos formas de bien común: el colectivo, que asegura la conservación del todo social, y el distributivo, que reparte bienes a los particulares; 3) tres tipos de relaciones estructuran la dinámica de las dos formas de bien común, reguladas por sendas formas de justicia: de los miembros al todo social (justicia general), del todo social a los miembros (justicia distributiva), de los miembros entre sí (justicia conmutativa); 4) "Si el acto de justicia consiste en dar a cada uno lo suyo, es porque dicho acto supone otro precedente, por virtud del cual algo se constituye en propiedad de alguien” (Contra Gentiles, II, 28); 5) “El acto por el cual se constituye inicialmente algo en propio de alguien, no puede ser un acto de justicia” (Contra Gentiles, II, 28); la razón de débito se encuentra antes en la ley natural, los contratos, los servicios, las promesas, disposiciones legales, etc.; 6) el derecho no es la ley, sino la “cosa misma”, la realidad, el objeto debidos: cosas u objetos 
corporales e incorporales, acciones, omisiones..., todo aquello sobre lo cual el hombre puede decir mío, tuyo, suyo, y que simultáneamente sea objeto o contenido de las relaciones intersubjetivas; 7) las normas son apenas mensura iuris, medidas de las cosas debidas; 8) es preciso indagar más allá de las normas para hallar la plenitud de los derechos... Tomás propone principios prudenciales para casos de justicia distributiva y conmutativa, para las funciones del juez, del testigo, del abogado, etc.

\subsubsection{La prudencia militar}

Prolongación de la gubernativa, esta prudencia conoce y ordena las acciones guerreras tanto del gobernante como de los jefes del ejército y de los soldados. El pequeño tratado sobre la guerra, de la q. 40 II-II, presenta los principios y reglas que deben guiar el uso de la violencia justa: 1) Para que la guerra sea justa se requiere la autoridad del príncipe, a quien compete "defender el bien público" de la ciudad, del reino o de la provincia; 2) se requiere causa justa (vindicar injurias, atropellos o robos); 3) que sea recta la intención de los contendientes: para promover el bien y evitar el mal, por deseo de paz o para frenar a los malos y favorecer a los buenos; 4) la mala intención hace injusta la guerra: el deseo de dañar, la crueldad de vengarse, el ánimo implacable, la ferocidad en la lucha, la pasión de dominar...; 5) deben prohibirse los ejercicios militares (o simulacros) peligrosos que dan lugar a muertes y pillajes; 6) "bajo ningún título les es permitido a los clérigos tomar parte en la guerra”, a no ser para exhortar, absolver y otros auxilios espirituales; 7) hay derechos de guerra y pactos que deben cumplirse, incluso entre enemigos; 8) se puede engañar al enemigo ocultando propósitos o intenciones; 9) en defen- sa del bien público es lícito hacer guerra en días festivos si la necesidad lo exige.

\subsection{Prudencia política}

\subsubsection{De los ciudadanos}

Esta prudencia política en sentido propio, parte también del conocimiento tanto de los datos de la situación como de la experiencia histórica y el saber de las “autoridades” del pasado. El ciudadano como tal y el "nosotros" de la "multitud" deben partir de algunos principios y reglas mínimos derivados de esa experiencia y de ese saber: 1) la justicia general compromete a cada uno en la construcción y mantenimiento del bien común, aportando cuanto las leyes prevén como los distintos hábitos operativos de la personalidad moral adquirida; 2) "el pueblo es asamblea de la multitud, asociada por consenso de acuerdo con el derecho y por comunión de utilidad" (I-II, 105, 2); 3) los ciudadanos vigilan el bien común colectivo, exigen distribuciones proporcionadas a las distintas situaciones particulares y generan abundancia mediante el intercambio de bienes; 4) para que pueda haber intercambios, los ciudadanos deben poseer medios de vida; 5) aunque el uso de las cosas exteriores debe ser común, cada uno debe poseer cosas propias con fines de administración y distribución (II-II, 66, 2); 6) el pueblo debe vigilar que los gobernantes no se conviertan en tiranos, pero "si el tirano no comete excesos, es preferible soportar temporalmente una tiranía moderada que oponerse a ella, porque tal oposición puede implicar peligros mucho mayores que la misma tiranía” (De Regno, I, 6); 7) se debe resistir al tirano y no guardarle el "pacto", pero no se debe actuar por presunción particular de alguno; 8) la sedición (stasis) o fragmentación del cuerpo social es la peor amenaza a la unidad del pueblo. 
Las recomendaciones de Tomás para la "prudencia política” frente a la tiranía hacen recordar el análisis que hace George Orwell en la Rebelión en la granja cuyo mundo narrado nos lleva al insólito ambiente "político" de las animales de la granja de los Jones, que se sublevan contra sus dueños humanos y los vencen, liderados por un viejo cerdo sabio (Viejo Mayor o Willingdon Beauty). Los cerdos de la república animal diseñan un Estado-policía en el que "todo lo que no es obligatorio está prohibido”. En la nueva sociedad los animales son iguales, "pero algunos son más iguales que otros”. La rebelión fracasará al surgir entre los distintos animales rivalidades y envidias, y al aliarse algunos con los amos derrocados, traicionando su identidad e intereses zoológicos. La mayoría de los ingenuos zoopolíticos ignoraban lo que había escrito Tomás: "Suele suceder en la tiranía que el tirano posterior resulte peor que su precedente, pues no sólo no suprime las cargas anteriores, sino que él mismo prepara otras mayores en su malvado corazón” (De Regno, 1,6).

\subsubsection{De los grupos restringidos intrapolíticos}

Dentro de la "prudencia política", que vincula a cada ciudadano con el pueblo con miras al bien común político, se dan formas de prudencia de grupos restringidos o de "comunidades de amistad”, como la familia, las relaciones de trabajo, los gremios, las cofradías, las órdenes religiosas, etc., que viven en el seno de la sociedad política, pero que tienen "bienes comunes" propios, a veces apuntando a fines más altos que la república. Su accionar prudencial debe tener en cuenta, como punto de partida, algunos principios y reglas: 1) Como la sociedad política no es la comunidad humana y mucho menos la comunidad del universo - hacia las cua- les debe abrirse cada persona-, y como además la sociedad política no es el fin último, las personas deben buscar otros "bienes comunes" que les permitan afirmar sus identidades o trascender los límites de las organizaciones políticas; 2) "El hombre no se ordena a la comunidad política con todo su ser y con todas sus cosas: y por consiguiente no es necesario que cualquier acto suyo sea meritorio o demeritorio en relación con la comunidad política, sino que todo lo que el hombre es, y todo lo que puede y tiene, debe ordenarse a Dios" (I-II, q. 21, 4); 3) el "bien común” de la sociedad política es el fin del hombre en la medida en que el hombre es parte de esa comunidad, como ciudadano; pero si esa comunidad no recoge en toda su plenitud al hombre o lo que implica la dignidad de la persona, el bien propio de cada uno excede la ordenación política; 4) si bien "todo hombre es para todo hombre un familiar y amigo" - lo que genera simpatías espontáneas entre congéneres-, las exigencias existenciales de la amistad no son realizables a nivel universal ni siquiera a nivel de la sociedad política: la benevolencia, la reciprocidad y la comunidad de intereses no se dan efectivamente sino entre próximos, en relaciones con rostro, no anónimas; 5) la familia (en cuyo seno las amistades son más fuertes) es el "útero espiritual” de las personas, y su bien común es el medio natural tanto para engendrar al hijo como para educarlo y conducirlo al estado de perfección que exige la autonomía prudencial; 6) el hombre se encuentra ordenado a distintos "bienes comunes” con distinta función medial, no reductibles el uno al otro, con diferentes exigencias de "amistad"; 7) los respectivos reagrupamientos humanos, aun estando asociados entre sí, deberán gozar de la necesaria autonomía y protección por parte de la sociedad política; 8) un bien común no puede absorber o anular los demás. 
Los "bienes comunes" selectivos o especializados, en el interior del "bien común” político o más allá de éste, abiertos eventualmente a comunidades de espíritus que no se encuentran como ciudadanos, sino como hombres, como creyentes, como cultivadores de valores, como miembros de "cuerpos místicos” o de “cosmópolis”, expresan el aserto tomasiano de que el hombre (el "animal más comunicativo”) nace social, con aptitud "multisocial”, y se hace luego parcialmente político. Lo político no absorbe todo lo social. No hay univocidad entre social y político, entre sociedad y polis, entre sociedad y república. No podrá confundirse nunca la "seguridad del Estado" con la "seguridad de la sociedad”, de la comunidad, ni el orden público con el orden social, ni la paz del Estado como la paz social, ni ser buen ciudadano con ser persona humana. Jürgen Habermas en, Teoría y praxis, descubre que Tomás de Aquino, al legitimar un cambio de vocabulario, “transforma la política aristotélica en una filosofía de lo social” en la cual la polis o Estado queda relativizada y trascendida. Ese cambio clave consistió en haber preferido la traducción del zoon politikon por "animal social”.

\section{Prudencia política tomasiana y "laberinto colombiano"}

Norberto Bobbio, en El problema de la guerra y las vías de la paz, comenzaba comentando la opinión de Wittgenstein sobre la tarea de la filosofía: “enseñar a la mosca a salir de la botella”, representación global de la vida humana. De acuerdo con la imagen, el filósofo estaría fuera de la botella y sabría hacia dónde guiar a la mosca. Bobbio pensaba que era posible otra metáfora: la del pez en la red, que se debate boqueante sin saber que no hay salida y que cuando la red se abra, no hallará liberación, sino muerte. El filósofo lo sabe y les recomienda a los peces aprovechar lo que les queda de vida y esperar la muerte con serenidad. Pero Bobbio descubre una tercera metáfora: la del laberinto, que tiene alguna salida, pero ni el filósofo sabe cuál es, pues él también está en la misma situación de los demás. Su tarea es la del prudente que enseña “a coordinar los esfuerzos, a no arrojarse de cabeza a la acción, y al mismo tiempo a no demorarse en la inacción, a hacer elecciones razonadas, a proponerse, a título de hipótesis, metas intermedias, corrigiendo el itinerario durante el trayecto si es necesario, a adaptar los medios al fin, a reconocer los caminos equivocados y abandonarlos una vez reconocidos como tales”.

Es posible que el prudencialismo tomista, sin desdeñar la habilidad del filósofo de la botella que cuenta con algunas certezas, sienta profunda simpatía por el filósofo del laberinto. Porque, en cuanto filósofo especulativo, el tomista parece estar convencido de "cómo son las cosas", su papel se parece bastante al del primer filósofo. Porque, como filósofo práctico, no parece seguro de verdades inmutables y es afectado por la incertidumbre, el prudente tomista actúa como el filósofo del laberinto, cuyas tareas son precisamente las del ejercicio de la prudencia, que exige "no arrojarse de cabeza en la acción”, “no demorarse en la inacción” y “adaptar los medios al fin”.

Tomás sugería una posible cuarta imagen de la vida humana: la del barco, que no se hizo para estar seguro en el puerto, sino para adentrarse, con todos los riesgos, en altamar (I-II, 2, 5). El barco tomasiano era, sin duda, un navío de su época, no un crucero moderno. El filósofo prudente lo que hace es reco-

3 Norberto Bobbio, El problema de la guerra y las vías de la paz (Barcelona: Gedisa, 1981) p. 22. 
mendar al timonel de ese barco que debe llevarlo a buen puerto, a través del proceloso mar y con la azarosa ayuda de los vientos. "La nave, que se mueve por el impulso de vientos diversos hacia lugares distintos escribe Tomás-, no llegaría al fin previsto si no fuera dirigida hacia el puerto por un timonel competente” (De Regno, I, 1). Esta imagen naviera es utilizada varias veces por Tomás como metáfora de la prudencia gubernativa en sus distintas especies.

En 2003, el PNUD (Programa de las Naciones Unidas para el Desarrollo) publicó El conflicto, callejón con salida, Informe Nacional de Desarrollo Humano para Colombia, bajo la dirección de Hernando Gómez Buendía. El título recupera la imagen del laberinto, y el representante del PNUD, en la presentación, alude a la "carta de navegación” que pretende ser el abultado documento de 500 páginas. Así, pues, una imagen del filósofo prudente de Bobbio y la imagen del gobernante-navegante de Tomás. En el laberinto no hay ruta segura y la brújula no funciona; y en el barco hay "carta de navegación” y seguramente brújula, pero nadie garantiza vientos ni oleajes. En ambos casos, hay una seguridad mínima: se sabe a dónde se quiere llegar (hay salida, hay puerto), pero la incertidumbre es alta: ¿dónde está la salida? ¿tenemos vientos y oleajes favorables?

El libro parece un deliberado ejercicio de “prudencia política” integral en el sentido expuesto, que ensambla elementos análogos a los del organon prudentiae aquiniano: la primera parte presenta una mirada a la historia y al contexto político (cap. 1), junto con una mirada a la geografía y a las diferencias regionales (cap. 2), para apreciar mejor la creciente degradación del conflicto (cap. 3) (“memoria”, “inteligencia”); la segunda parte —con atención a la experiencia internacio- nal- analiza la relación entre conflicto armado y desarrollo humano (cap. 4), observando el impacto sobre las víctimas (cap. 5) y explicando cómo el desarrollo humano sería la salida del laberinto (cap. 6) ("razón”, “docilidad”, “providencia”); la tercera parte detalla políticas, programas o medidas concretas que, a la luz de lo anterior, serían más adecuadas para atenuar o corregir los daños y facilitar la solución del conflicto armado (seguridad, justicia, atención a víctimas, secar finanzas de la guerra, combatir narcotráfico, fortalecer gobernabilidad local, resolver tensiones sociales...) (“solercia”, "providencia”, “cautela”); y la cuarta parte se centra en el papel que podrían desempeñar el sistema educativo y los medios de comunicación, sociedad civil y comunidad internacional (“circunspección”, “providencia”, “cautela”)...

Junto a la "prudencia política”, que urge la participación activa de las distintas fuerzas sociales (con llamado a las organizaciones locales y a las distintas comunidades), se enfatiza el papel de la "prudencia gubernativa” en sus aspectos "legislativo" y de "justicia”, sin descartar la importancia de la "prudencia militar", aun reconociendo que los cuatro ejércitos (Fuerzas Armadas, AUC, FARC, ELN) llevan perdida la guerra, que no cumple los requisitos del ius ad bellum ni del ius in bello tomasianos. Se trata de una larga seditio que fragmenta la unidad de la patria. La salida del laberinto (“callejón”) no es de ejércitos vencedores. Como escribe Bobbio: "La única cosa que el hombre del laberinto ha aprendido de la experiencia (supuesto que haya llegado a la madurez mental de aprender la lección de la experiencia) es que hay calles sin salida: la única lección del laberinto es la de la calle bloqueada"4, y una de esas calles bloqueadas es precisamente la de la guerra. 
El libro del PNUD indica hacia dónde guiar la salida del laberinto ("el desarrollo" y la participación de todos, tanto en el fortalecimiento del "bien común colectivo" como en la acción de la "justicia distributiva" en cuanto justicia social); y cómo maniobrar el barco para que no zozobre entre los agentes del conflicto ("humanizar la guerra mientras dure”, pactar la paz negociando).

Las dos prudencias políticas (gubernativa y ciudadana), en sinergia multilateral, son las únicas maneras de que la salida del callejón se vaya concretando y el rumbo del barco no se desvíe, así haya que seguir esperando. Cuando Epimeteo destapó la caja de Pandora no quedó sino la Esperanza, y ésta es una virtud cristiana que refuerza la voluntad prudencial de acertar en la búsqueda y elección de los medios para lograr el objetivo de la justicia general: reconstruir el bien común colectivo, para que recupere su fuerza distributiva.

4 Bobbio, El problema ..., p. 23. 